\title{
ESS \\ A Procedure for Evaluating the Capacity Associated with Battery-Type Electrode and Supercapacitor-Type One in Composite Electrodes
}

\author{
I. Aldama, ${ }^{1}$ V. Barranco, ${ }^{2}$ J. Ibañez, ${ }^{2}$ J. M. Amarilla, ${ }^{1}$ and J. M. Rojo ${ }^{1,}{ }^{1, *, z}$ \\ ${ }^{I}$ Instituto de Ciencia de Materiales de Madrid (ICMM), Consejo Superior de Investigaciones Científicas \\ (CSIC), Cantoblanco, E28049-Madrid, Spain \\ ${ }^{2}$ Centro Nacional de Investigaciones Metalúrgicas (CENIM), CSIC, E28040-Madrid, Spain
}

\begin{abstract}
This paper provides a procedure for evaluating the capacity or charge of composites consisting of battery-type electrode and supercapacitor-type one. The composites, which are binder-free flexible materials, consist of cobalt oxide $\left(\mathrm{CoO}_{\mathrm{x}}\right)$ electrodeposited on the fibers of a carbon cloth (CC). The deposited $\mathrm{CoO}_{\mathrm{x}}$ shows battery-type response. The CC substrate shows supercapacitor-type one. The procedure here reported is based on galvanostatic charge/discharge measurements. It is easier, less laborious and faster than the procedure based on the kinetic study by cyclic voltammetry. The two procedures are compared. The dependences of the specific capacities as functions of the current density and voltage scan rate show similar patterns. The contribution of the two types of materials to the specific capacity of the complete electrode is discussed. The electrodedeposited $\mathrm{CoO}_{\mathrm{x}}$ contributes increasing the specific capacity of the composites at low current densities. The CC substrate dominates the specific capacity of the composites at high current densities.

(C) The Author(s) 2018. Published by ECS. This is an open access article distributed under the terms of the Creative Commons Attribution 4.0 License (CC BY, http://creativecommons.org/licenses/by/4.0/), which permits unrestricted reuse of the work in any medium, provided the original work is properly cited. [DOI: $10.1149 / 2.1131816 \mathrm{jes}]$

(cc) BY
\end{abstract}

Manuscript submitted October 8, 2018; revised manuscript received November 29, 2018. Published December 29, 2018

It is known that for battery-type electrodes the insertion/extraction of ions into/from the particle bulk, accompanied by a faradaic process (reduction/oxidation of some electrode atoms) shows a diffusioncontrolled kinetic, which can be slow. The cyclic voltammogram $(\mathrm{CV})$ shows redox peaks with currents depending linearly on $v^{1 / 2}$, where $v$ is the voltage scan rate. Pseudocapacitance is also a faradaic process involving reduction/oxidation reactions and ion insertion/extraction but at the particle surface or near the particle surface only; those insertion/extraction reactions can be fast. ${ }^{1-5}$ The $\mathrm{CV}$ of a pseudocapacitortype electrode shows a distorted rectangular shape with very broad peaks; the currents measured depend linearly on $v$. Hence, the kinetic of battery-type electrodes is clearly different from that of pseudocapacitor-type ones. Nevertheless, as the particle size of battery-type electrodes decreases to a few nanometers, a change in behavior from battery to pseudocapacitor has been observed. ${ }^{6}$ The change seems to be the consequence of the dominance of the surface over the bulk ${ }^{7,8}$ and several materials showing this "extrinsic" pseudocapacitive behavior have been reported. ${ }^{9-12}$ The relative contribution of the battery response and pseudocapacitor one can be evaluated from CV measurements. In particular, by measuring the current $(I)$ at each potential $(V)$ for several voltage scan rates $(v)$ and then, by analyzing the equation $I(V)=k_{1} v+k_{2} v^{1 / 2}$, where the first and second term stand for the contributions from the surface-controlled kinetic and the diffusion-controlled one, respectively. Double layer capacitor electrodes, which are based on the formation of the double layer at the electrolyte/electrode interface, show also a surface-controlled kinetic and hence, $I(V)$ depends linearly on $v$, like the pseudocapacitor-type electrodes. ${ }^{2}$ Therefore, a supercapacitor electrode, either pseudocapacitor electrode or double layer one, can be differentiated from a battery electrode from the kinetic point of view. If both electrochemical responses, supercapacitor and battery, are involved as a consequence of the small size of the electrode particles, their respective contributions can be assessed as $k_{1} v / I(V)$ for the supercapacitor response and as $k_{2} v^{1 / 2} / I(V)$ for the battery one. ${ }^{6-12}$

This paper deals with composite electrodes showing a batterytype response together with a supercapacitor-type one. The two responses do not come from the presence of nanometer electrode particles but from the presence of two different electrode materials, one battery-type material and another supercapacitor-type one. The study provides a procedure for evaluating the capacity or charge due to

\footnotetext{
*Electrochemical Society Member
}

${ }^{\mathrm{z} E}$ E-mail: jmrojo@icmm.csic.es the two components and their contribution to the capacity of the complete electrode. The procedure, which is based on galvanostatic charge/discharge (GCD) measurements, is compared with the conventional procedure based on $\mathrm{CV}$ measurements.

The composites consist of Co oxide $\left(\mathrm{CoO}_{\mathrm{x}}\right)$ deposited on the fibers of a carbon cloth (CC). The $\mathrm{CoO}_{\mathrm{x}}$ usually referred as the spinel $\mathrm{Co}_{3} \mathrm{O}_{4}$ but also as the amorphous Co oxide-hydroxide has been considered for long time as an active electrode material for supercapacitors (pseudocapacitors). ${ }^{13-43}$ However, its electrochemical response is battery-type ${ }^{44-46}$ and $\mathrm{CoO}_{x}$ can be used as positive electrode material in hybrid asymmetric supercapacitors. ${ }^{4-49}$ The $\mathrm{CoO}_{\mathrm{x}}$ can be combined with carbons leading to $\mathrm{CoO}_{\mathrm{x}} / \mathrm{C}$ composites. ${ }^{33,36-40,42}$ That oxide can be deposited on a substrate by chemical procedures ${ }^{14,16,18-22,34,35}$ and also by electrochemical ones. ${ }^{13,23-33,36}$ Regarding the substrate, carbon fabric or carbon cloth (CC) is chosen in this paper because $\mathrm{CC}$ is flexible, conductive and porous. The $\mathrm{CC}$ consists of woven carbon threads that provide self-standing ${ }^{50-53}$ and can be folded several times with the same electrochemical behavior. ${ }^{54-57}$ Moreover, the CC shows electrical conductivity on the order of magnitude of $0.1 \mathrm{~S} \mathrm{~cm}^{-1}$ and large specific surface area (ca. $1000 \mathrm{~m}^{2} \mathrm{~g}^{-1}$ ), which comes mainly from the presence of big micropores $(0.7-2 \mathrm{~nm}){ }^{53}$ The $\mathrm{CC}$ is also light and inexpensive. This substrate has been chosen for chemical depositions ${ }^{58-64}$ and for electrodepositions ${ }^{45,65}$ of active electrode materials.

\section{Experimental}

The commercial $\mathrm{CC}$ is an activated carbon manufactured by Carbongen SA. Circular pieces of $12 \mathrm{~mm}$ in diameter, ca. $0.6 \mathrm{~mm}$ in thickness, and $12 \mathrm{mg}$ in weight were punched out. The specific surface area of $1100 \mathrm{~m}^{2} \mathrm{~g}^{-1}$ comes from the presence of big micropores $(0.7-2 \mathrm{~nm})$ and small mesopores $(3-4 \mathrm{~nm})$. The electrical conductivity, of $0.15 \mathrm{~S} \mathrm{~cm}^{-1}$ measured in the perpendicular direction of the $\mathrm{CC},{ }^{53}$ is sufficient to perform the electrodepositions.

Electrodepositions of $\mathrm{CoO}_{\mathrm{x}}$ on the circular $\mathrm{CC}$ pieces were carried out by cyclic voltammetry (potentiodynamic procedure) in a threeelectrode configuration. The $\mathrm{CoO}_{\mathrm{x}}$ precursor was $\mathrm{Co}$ acetyl acetonate, $\left[\left(\mathrm{CH}_{3} \mathrm{CO}\right)_{2} \mathrm{CH}\right]_{2} \mathrm{Co}$, reagent grade from Sigma-Aldrich. This precursor was chosen for increasing the amount of the deposited $\mathrm{CoO}_{\mathrm{x}}$ as compared with other precursors, e.g. the cobalt sulfate. ${ }^{45}$ A 0.04 $\mathrm{M}$ aqueous solution of Co acetyl acetonate was prepared. Before each electrodeposition, the $\mathrm{CC}$ piece was in contact with $5 \mathrm{ml}$ of the aqueous solution under primary vacuum (0.1 Torr) for $30 \mathrm{~min}$. 

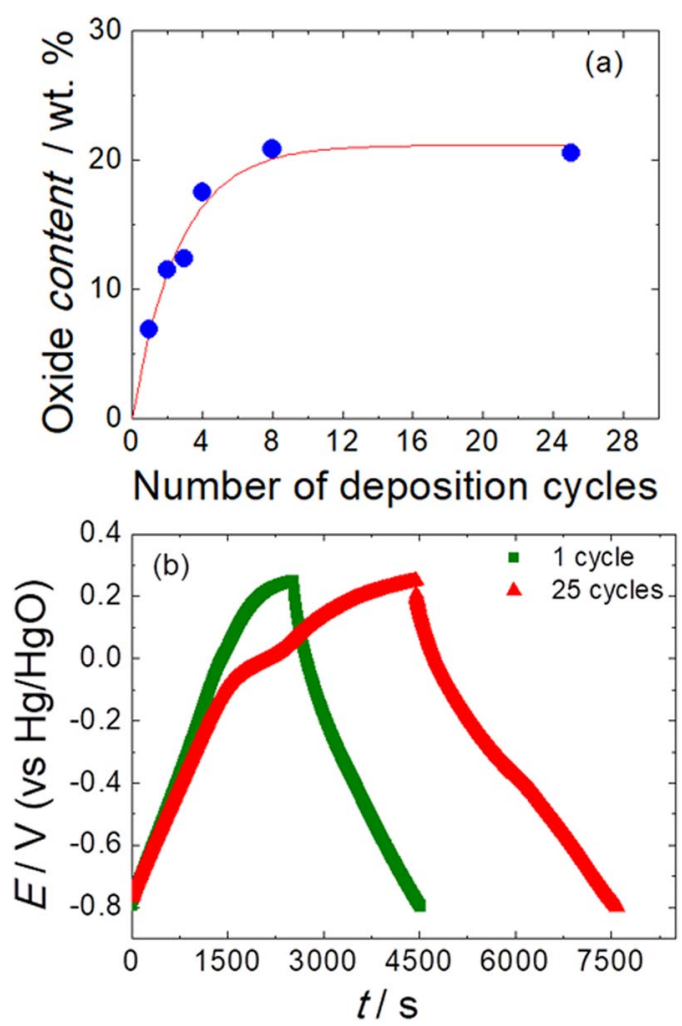

Figure 1. Dependence of the content of deposited $\mathrm{CoO}_{\mathrm{x}}$ as a function of the number of electrodeposition cycles; the red line is a guide to the eye (a). Galvanostatic charge /discharge plots recorded at $0.9 \mathrm{~mA} \mathrm{~cm}-2$ on the composites obtained after 1 and 25 electrodeposition cycles (b).

In the three-electrode configuration, the $\mathrm{CC}$ piece was the working electrode, gold wire was the counter electrode and $\mathrm{Ag} / \mathrm{AgCl}$ was the reference electrode. Each electrodeposition cycle was performed from the open circuit potential $(\mathrm{OCP}=0.15 \mathrm{~V})$ to $-0.95 \mathrm{~V}$ and then from this voltage to the OCP, both runs recorded at the voltage scan rate of $0.5 \mathrm{mV} \mathrm{s}^{-1}$. The electrodeposition cycle was repeated a certain number of times, up to 25 . Once the electrodeposition was over, the samples were taken out from the three-electrode cell, washed with distilled water and dried at $120^{\circ} \mathrm{C}$ for $2 \mathrm{~h}$ in still air. The load of the deposited oxide was calculated from the difference of weights of the electrodeposited samples and the weight of the bare CC.

The resulting samples, consisting of $\mathrm{CoO}_{\mathrm{x}}$ deposited on the $\mathrm{CC}$ were characterized by scanning electron microscopy (SEM) equipped with energy dispersive X-ray spectroscopy (EDS) in a FEG HITACHI S-4800 instrument. The images were obtained in the secondary electron mode. The samples were also characterized by X-ray diffraction on a Bruker-AXS D8 equipment with $\mathrm{Cu} \mathrm{K} \alpha$ radiation $(\lambda=1.5418 \AA)$

The electrochemical study of the $\mathrm{CoO}_{\mathrm{x}} / \mathrm{CC}$ composites was made in a three-electrode configuration. The composites were the working electrodes. Platinum wire was the counter electrode. $\mathrm{Hg} / \mathrm{HgO}$ was the reference electrode. The electrolyte was $1 \mathrm{M} \mathrm{KOH}$ aqueous solution. Cyclic voltammograms were recorded at voltage scan rates in the range $0.5-10 \mathrm{mV} \mathrm{s}^{-1}$. Galvanostatic charge/discharge measurements were performed at current densities in the range $0.9-35 \mathrm{~mA} \mathrm{~cm}^{-2}$.

\section{Results and Discussion}

Figure 1a shows the dependence of the amount of deposited oxide as a function of the number of potentiodynamic cycles applied during the electrodeposition. The amount of deposited oxide increases with the number of cycles up to 8 cycles. Above 8 cycles, that amount is constant and reaches the value of $20.8 \mathrm{wt} \%$, which is slightly higher

\section{Table I. Number of electrodeposition cycles applied, oxide content} and specific capacity of the composites $\left(Q_{E}\right)$.

\begin{tabular}{ccc} 
Number of cycles & Oxide content $(\mathrm{wt} \%)$ & $Q_{E}\left(\mathrm{~mA} \cdot \mathrm{h} \cdot \mathrm{g}^{-1}\right)$ \\
\hline 1 & 6.9 & 40 \\
2 & 11.5 & 43 \\
3 & 12.4 & 44 \\
4 & 17.6 & 48 \\
8 & 20.8 & 33 \\
25 & 20.5 & 35
\end{tabular}

than the maximum value obtained by using the same electrodeposition procedure but with cobalt sulfate as precursor. ${ }^{45}$

The specific charge or specific capacity of the as-prepared composites was deduced from galvanostatic charge/discharge plots during the discharge run (Figure 1b), according to of the equation

$$
Q_{E}=I \cdot t_{d} / m
$$

where $I(\mathrm{~A})$ is the current applied, $t_{d}(\mathrm{~s})$ is the time during the discharge run and $m(\mathrm{~g})$ is the mass of the composite. The specific capacity of the bare $\mathrm{CC}$ is $34 \mathrm{~mA} \mathrm{~h} \mathrm{~g}^{-1}$. The specific capacity of the prepared composites increases with the increase in the amount of the deposited $\mathrm{CoO}_{\mathrm{x}}$ (Table I), that reaching a value of $48 \mathrm{~mA} \mathrm{~h} \mathrm{~g}^{-1}$ for the composite with $17.6 \mathrm{wt} \%$ of $\mathrm{CoO}_{\mathrm{x}}$. For higher oxide contents, the specific capacity decreases. Therefore, the sample with $17.6 \mathrm{wt} \%$ of $\mathrm{CoO}_{\mathrm{x}}$, which was obtained after 4 eletrodeposition cycles, is the best performant. This electrode, which is called here-after as $\mathrm{CoO}_{\mathrm{x}} / \mathrm{CC}$, was chosen for checking the procedure reported in this paper for evaluating the capacity associated with the deposited $\mathrm{CoO}_{\mathrm{x}}$, with the $\mathrm{CC}$ substrate and with the complete electrode. All the composites were flexible electrodes as a consequence of the choice of $\mathrm{CC}$ as substrate.

The CC substrate consists of woven carbon fibers with 6-7 $\mu \mathrm{m}$ in diameter (Figure 2a). After 4 electrodeposition cycles the fibers are completely covered by the $\mathrm{CoO}_{\mathrm{x}}$ (Figure 2b). The deposited oxide, which is amorphous as deduced from X-ray diffraction, shows sheets that appear aggregated giving rise to an open structure. The thickness and length of the sheets are ca. $4 \mathrm{~nm}$ and $60 \mathrm{~nm}$, respectively. The open structure shows voids between the sheets of ca. $30 \mathrm{~nm}$ size (Figure 2c). This structure is similar to that reported for $\mathrm{CoO}_{\mathrm{x}}$ deposited on other substrates. ${ }^{16-22}$ The presence of voids favors the access of the electrolyte to the interior of the sheets and also to the interior of the carbon fibers. An analysis by EDS confirmed that the $\mathrm{KOH}$ electrolyte was located on the deposited oxide, the external surface and also the interior of the carbon fibers.

The cyclic voltammogram (CV) for the bare $\mathrm{CC}$ shows a nearly rectangular shape with slightly higher values of the current at negative potentials (Figures $3 \mathrm{a}$ and $3 \mathrm{~b}$ ). The rectangle is characteristic of double layer capacitance. The slight distortion of the rectangle at negative potentials is characteristic of a pseudocapacitive contribution associated with the presence of oxygen groups on the surface of the CC. ${ }^{53}$ Therefore, the whole $\mathrm{CV}$ is characteristic of a supercapacitor electrode, double layer capacitance plus pseudo-capacitance. This material can be characterized by its specific charge or capacity $\left(34 \mathrm{mAh} \mathrm{g}^{-1}\right)$ and also by its specific capacitance $\left(140 \mathrm{~F} \mathrm{~g}^{-1}\right)$. The $\mathrm{CV}$ for the $\mathrm{CoO}_{\mathrm{x}} / \mathrm{CC}$ sample (Figures $3 \mathrm{a}$ and $3 \mathrm{~b}$ ) shows on the anodic branch (run of charge), a constant value of the current in the potential range from -0.8 to $-0.2 \mathrm{~V}$ (supercapacitor response associated with the $\mathrm{CC}$ substrate) and an oxidation peak at ca. $0 \mathrm{~V}$ (battery response associated with the deposited $\mathrm{CoO}_{\mathrm{x}}$ ). On the cathodic branch (run of discharge), the $\mathrm{CV}$ shows the reduction peak and the constant value of the current. For potentials above $0.15 \mathrm{~V}$, the $\mathrm{CV}$ shows an irreversible increase in current associated with electrolyte decomposition evolving oxygen. This feature avoids the detection of any other peak ascribed to the $\mathrm{CoO}_{\mathrm{x}}$ in the potential range 0.2-0.4 V. ${ }^{14,28-30,33}$ Therefore, the CV for the $\mathrm{CoO}_{\mathrm{x}} / \mathrm{CC}$ sample shows the supercapacitor response and the battery one clearly differentiated, unlike the CVs reported for batterytype materials with particle sizes of a few nanometers. ${ }^{6-12}$ The concept 


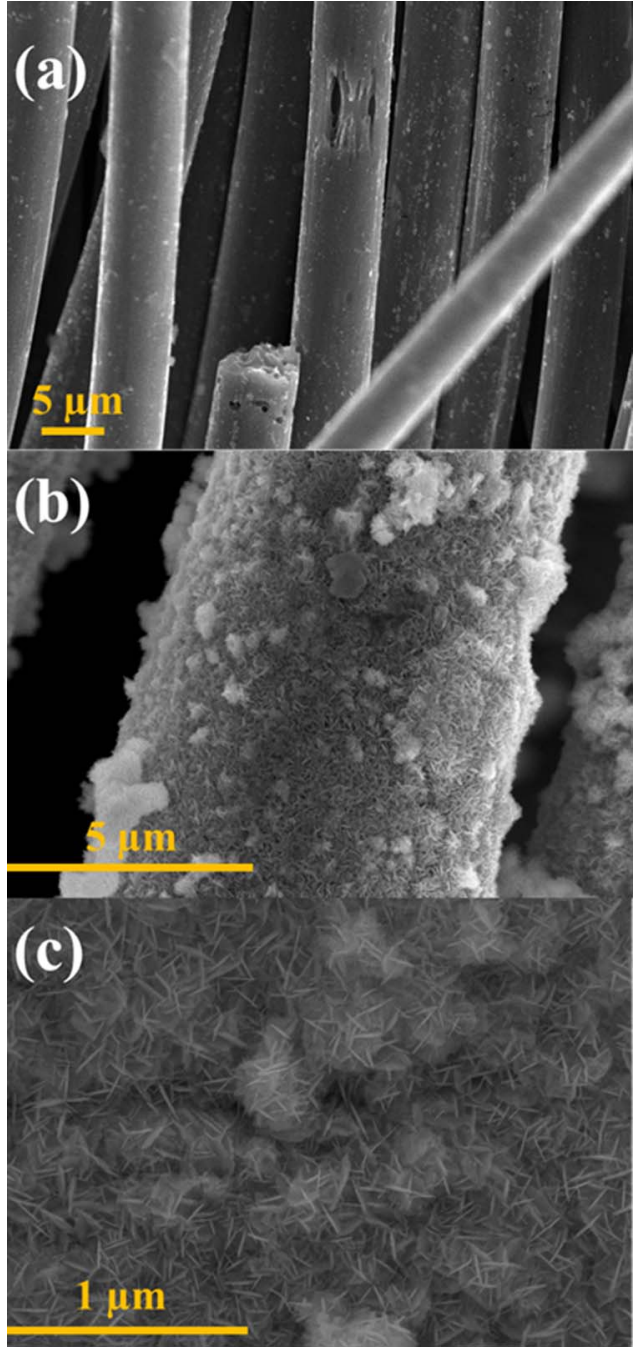

Figure 2. SEM micrographs of carbon fibers of the bare CC (a) and carbon fibers coated by the $\mathrm{CoO}_{\mathrm{x}}$ particles at two magnifications, low (b) and higher (c). The micrographs (b) and (c) stand for the $\mathrm{CoO}_{\mathrm{x}} / \mathrm{CC}$ sample that was obtained after 4 electrodeposition cycles.

of capacitance as the derivative of the charge with respect to the potential cannot be used for the narrow redox peaks of the deposited $\mathrm{CoO}_{\mathrm{x}}$. Those peaks can be characterized by its charge or capacity only. ${ }^{44}$ Therefore, the electrochemical responses due to the CC substrate and the deposited oxide can be compared in terms of charge or capacity only. ${ }^{45}$ Coming back to the CVs for both the composite and the substrate, Figure 3a compares the CVs for the two samples with the same geometric surface area (12 mm-diameter) but different masses. The agreement of the supercapacitive response of the composite with that of the bare substrate suggests that the pores of the $\mathrm{CC}$ are not covered by the deposited oxide. Figure $3 \mathrm{~b}$ compares the CVs in terms of current density, i.e. the same mass. The supercapacitive response of the composite (blue dotted line) shows lower values of current density than those of the bare substrate (black dotted line). However, if the $\mathrm{CV}$ of the bare substrate is normalized by $82 \mathrm{wt} \%$, which is the content of the $\mathrm{CC}$ in the composite, the values of current density (red solid line) agree with those of the supercapacitive response of the composite (blue dotted line). This result supports again that the pores of the $\mathrm{CC}$ are not covered by the deposited oxide and hence, the specific capacity of the composite depends on the content of the two components and the specific capacity of each component according to the rule of mixtures. This rule seems to be held for composites made from transition metal oxides and mesoporous carbons. ${ }^{66}$ Our
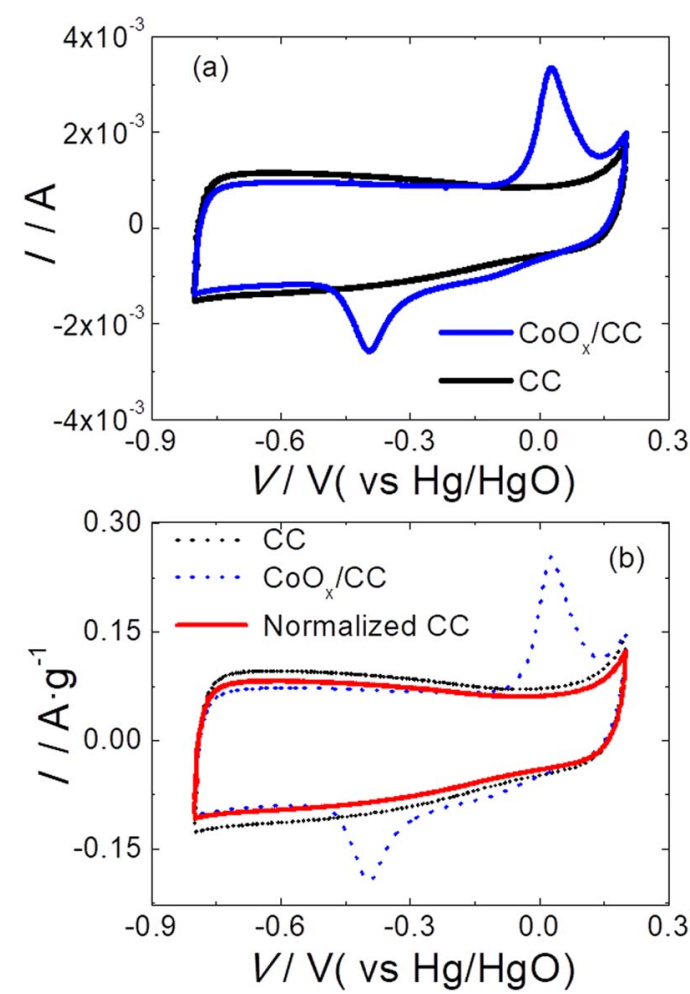

Figure 3. Cyclic voltammograms recorded at $0.5 \mathrm{mV} \mathrm{s}^{-1}$ on the $\mathrm{CoO}_{\mathrm{x}} / \mathrm{CC}$ composite and the bare CC substrate. The ordinate axis is current in (a) and current density in (b).

$\mathrm{CC}$ shows an average micropore size of $1.7 \mathrm{~nm}$, which is close to the beginning of the mesoporous range, $2-50 \mathrm{~nm}$.

The $\mathrm{CV}$ for the $\mathrm{CoO}_{\mathrm{x}} / \mathrm{CC}$ composite was recorded at several voltage scan rates on the anodic run (Figure 4a). The current, $I$, increases with the increase of the voltage scan rate, $v$. The position of the peak shifts to higher potentials with the increase of $v$. To measure the current at each voltage, a straight line linking the maximum of the peaks was drawn and then, parallel lines to this straight line were also drawn (Figure 4a). From the crossings of the straight lines with the CVs, the $I$ values were measured for each $V$ value. Then, the $k_{1}$ parameter associated with the surface-controlled kinetic (supercapacitor response) and the $k_{2}$ parameter associated with the diffusion-controlled kinetic (battery response) were determined from the fittings of $I(V) / v^{0.5}$ vs. $v^{0.5}$ according to the equation

$$
I(V) / v^{0.5}=k_{1} \cdot v^{0.5}+k_{2}
$$

The fittings obtained for the potentials at the peak maximum and at $-0.3 \mathrm{~V}$ are shown as examples in Figure $4 \mathrm{~b}$. In the former case, the values obtained are $k_{1}=0.87 \mathrm{~F}$ and $k_{2}=0.14 \mathrm{~A} \mathrm{~V}^{-0.5} \mathrm{~s}^{0.5}$, pointing out that both, supercapacitor response and battery one are involved. In the latter case, $k_{1}=1.78 \mathrm{~F}$ and $k_{2} \approx 0$, evidencing that only the supercapacitor response is involved. Once the $k_{1}$ and $k_{2}$ values were deduced for each potential, the currents were calculated as $k_{1} v$ for the supercapacitive response (red closed circles in Figure 4c) and as $k_{2} v^{0.5}$ for the battery response (blue closed triangles in Figure 4c). The supercapacitive current shows values in all the potential range, i.e. from -0.8 to $0.15 \mathrm{~V}$. The battery current, however, shows values for potentials near the peak only, i.e. from -0.05 to $0.15 \mathrm{~V}$. This behavior is different from that reported for battery-type materials with particle sizes smaller than $10 \mathrm{~nm}^{6-8}$ and points out dominance of the battery response over the capacitive response for the deposited $\mathrm{CoO}_{\mathrm{x}}$. The particles of the deposited $\mathrm{CoO}_{\mathrm{x}}$ show thicknesses of ca. 4 $\mathrm{nm}$ and lengths of ca. $60 \mathrm{~nm}$, as deduced from the SEM results. So, the behavior observed for the deposited $\mathrm{CoO}_{\mathrm{x}}$ raises the question of which is the size threshold for the dominance of capacitive response 

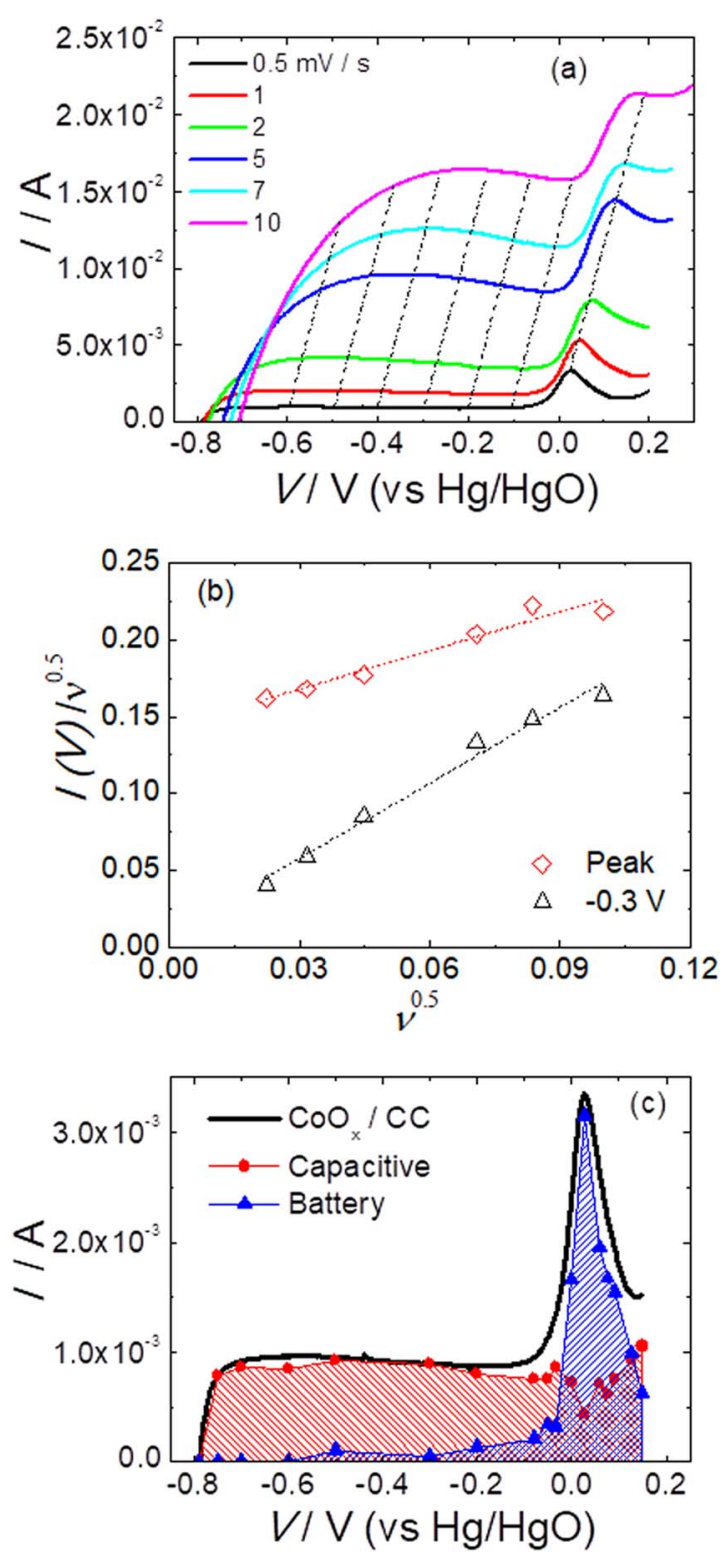

Figure 4. (a) Cyclic voltammograms obtained on the $\mathrm{CoO}_{\mathrm{x}} / \mathrm{CC}$ composite at several voltage scan rates on the anodic scan. (b) Fittings of $I(V) / v^{0.5}$ vs. $v^{0.5}$ according to the equation $I(V) / v^{0.5}=k_{1} v^{0.5}+k_{2}$ for obtaining the $k_{1}$ and $k_{2}$ parameter. The fittings are shown as examples for the currents measured at $-0.3 \mathrm{~V}$ and at the voltage of the peak on the anodic scan. (c) Capacitive currents (red closed circles) and battery currents (blue closed triangles) deduced from the fittings. The total current (black solid line) was obtained experimentally at $0.5 \mathrm{mV} \mathrm{s}^{-1}$

in battery-type materials. Moreover, the size threshold could depend on the particle shape and/or composition. ${ }^{6,9-12}$

The charges due to the supercapacitive response, $Q_{S C}$, and the battery response, $Q_{B}$, were obtained from integration of their respective areas, as shown as examples in Figure 4c. The charge due to the complete electrode, $Q_{E}$, was obtained from integration of the total current measured experimentally (black solid line in Figure 4c). The charge due to the bare substrate, $Q_{C C}$, was determined from integration of its $\mathrm{CV}$ (black solid line in Figure 3a). The values of the three charges, $Q_{S C}, Q_{B}$ and $Q_{E}$ on the one hand and the values of the $Q_{C C}$ on the other, all of them deduced from the CVs obtained at several voltage scan rates, are compared below with the values deduced for those charges from GCD plots obtained at several current densities.
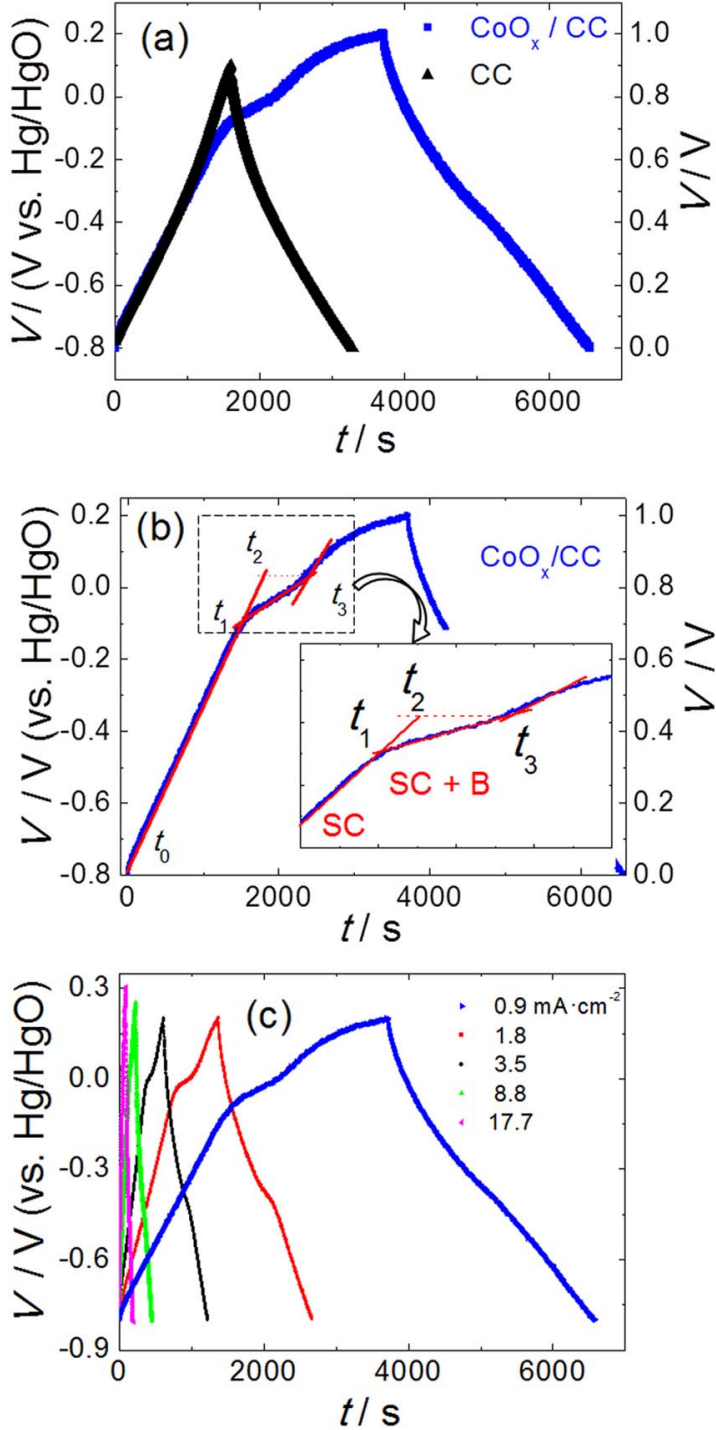

Figure 5. (a) Galvanostatic charge/discharge plots obtained at $0.9 \mathrm{~mA} \mathrm{~cm} \mathrm{~cm}^{-2}$ for the $\mathrm{CoO}_{\mathrm{x}} / \mathrm{CC}$ sample and for the bare CC substrate. (b) The expanded plot obtained for the $\mathrm{CoO}_{\mathrm{x}} / \mathrm{CC}$ sample on the run of charge. (c) The plots obtained for the $\mathrm{CoO}_{\mathrm{x}} / \mathrm{CC}$ sample at several current densities.

The GCD plots obtained at $0.9 \mathrm{~mA} \mathrm{~cm}^{-2}$ for the bare $\mathrm{CC}$ and for the $\mathrm{CoO}_{\mathrm{x}} / \mathrm{CC}$ composite are shown in Figure 5a. The values of the potential were measured in the three-electrode configuration (left vertical axis) and also in the two-electrode configuration (right vertical axis). The plot for the bare CC shows a triangular shape, slightly departing from the straight lines as a consequence of the pseudocapacitive contribution in addition to the double layer one, as already discussed. The plot on the run of charge for the $\mathrm{CoO}_{\mathrm{x}} / \mathrm{CC}$ composite shows a linear region followed by an inclining plateau, another linear region and finally another inclining plateau. A view of these features in an expanded scale is shown in Figure 5b. The linear increase of $V(t)$ from -0.8 to $-0.1 \mathrm{~V}$ (three-electrode cell) or from 0 to $0.7 \mathrm{~V}$ (two-electrode cell) is due to the supercapacitor response of the $\mathrm{CC}$ substrate. The inclining plateau at ca. $-0.05 \mathrm{~V}$ (three-electrode cell) and at ca. $0.75 \mathrm{~V}$ (two-electrode cell) is ascribed to overlapping of the battery response of the deposited $\mathrm{CoO}_{\mathrm{x}}$ and the supercapacitor response of the $\mathrm{CC}$ substrate. The plateau at higher potentials is due to electrolyte decomposition evolving oxygen. The same three features are observed in the discharge run but they are worse defined. Therefore, we have chosen the run of charge for measuring the capacity associated with the supercapacitor response, $Q_{S C}$, with the battery 

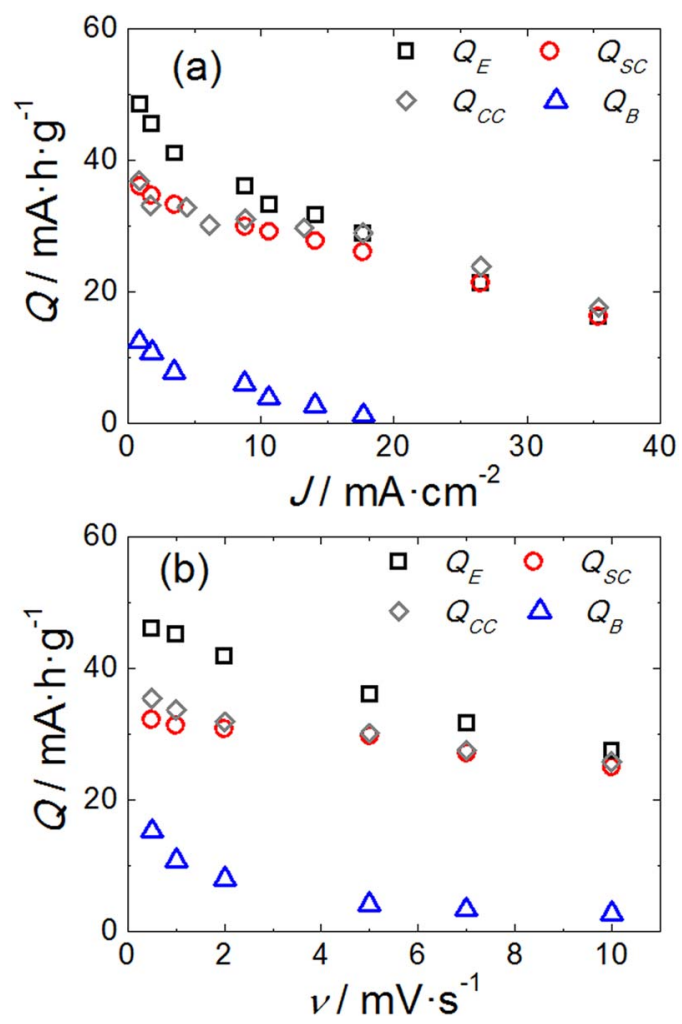

Figure 6. Dependence of the specific capacities as functions of the current density (a) and voltage scan rate (b). $Q_{S C}, Q_{B}$ and $Q_{E}$ stand for the specific capacity of the supercapacitor response, the battery one and the complete electrode response, all of them obtained for the $\mathrm{CoO}_{\mathrm{x}} / \mathrm{CC}$ composite. $Q_{C C}$ stands for the specific capacity of the bare $\mathrm{CC}$ substrate.

one, $Q_{B}$, and with the complete electrode, $Q_{E}$. In the period of time from $t_{0}$ till $t_{1}$ the supercapacitor response occurs only. This response continues till the time $t_{2}$. In the period of time from $t_{1}$ till $t_{3}$, the supercapacitor and battery response appear together. The capacity of the complete electrode is $Q_{E}=I \cdot\left(t_{3}-t_{0}\right)$. The capacity associated with the supercapacitor response is $Q_{S C}=I \cdot\left(t_{2}-t_{0}\right)$. Then, the capacity associated with the battery response is $Q_{B}=Q_{E^{-}} Q_{S C}=I \cdot\left(t_{3}-t_{2}\right)$. The potential range for the supercapacitor response, $\Delta V_{S C}$, is the difference of potentials measured at $t_{2}$ and $t_{0}$. The potential for the battery response, $V_{B}$, is the potential measured in the middle of the inclining plateau, between $t_{3}$ and $t_{1}$. The values of $Q_{E}, Q_{S C}$ and $Q_{B}$ decrease with the increase of the current density. Moreover, the shape of the plots becomes more triangular indicating a decrease of the battery contribution (Figure 5c). The values of $\Delta V_{S C}$ decrease with the increase of the current density in agreement with the trend usually observed for supercapacitors. The values of $V_{B}$ increase slightly with the increase of the current density; this trend agrees with the trend usually observed for batteries during the run of charge.

The values of $Q_{E}, Q_{S C}$ and $Q_{B}$ deduced from the GCD measurements are compared with those deduced from the $\mathrm{CV}$ ones in Figures $6 \mathrm{a}$ and $6 \mathrm{~b}$. The two plots show similar patterns. At low current densities and low voltage scan rates, the values of $Q_{E}$ are higher than those of $Q_{S C}$. This is explained by the presence of the deposited $\mathrm{CoO}_{\mathrm{x}}$, providing an additional capacity, $Q_{B}$. However, at current densities higher than $17 \mathrm{~mA} \mathrm{~cm}^{-2}$ and at voltage scan rates higher than $10 \mathrm{mV} \mathrm{s}^{-1}$, the values of $Q_{E}$ are similar to those of $Q_{S C}$. This is because the contribution of $Q_{B}$ decreases with the increase of the current density or voltage scan rate. The values of $Q_{C C}$, corresponding to the bare CC, agree with the values of $Q_{S C}$ determined from the $\mathrm{CoO}_{\mathrm{x}} / \mathrm{CC}$ composite.

Due to the fact that either $Q_{S C}$ and $\Delta V_{S C}$ or $Q_{B}$ and $V_{B}$ change with the increase of the current density, as deduced from the GCD

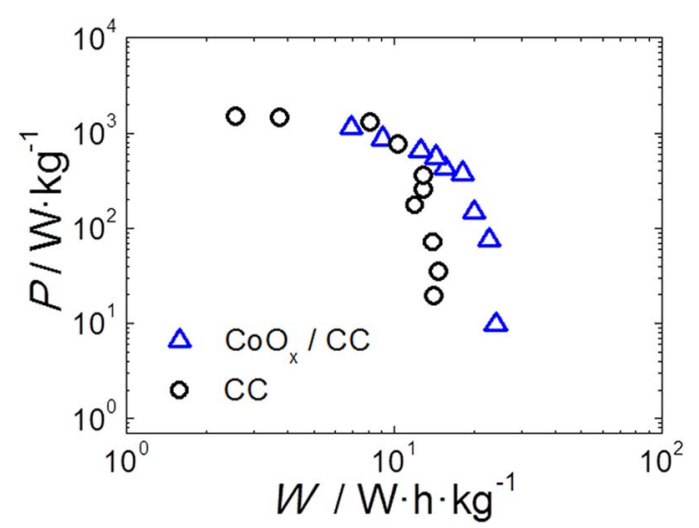

Figure 7. Specific power vs. specific energy for the $\mathrm{CoO}_{\mathrm{x}} / \mathrm{CC}$ composite and for the bare CC substrate.

plots, a procedure to analyze the two parameters together is through the specific energy and specific power of the composite. It is worth to mention that the specific energy and specific power here discussed deal with the composite only (one electrode), unlike the specific energy and specific power usually referred to two-electrode cells. In this paper, the specific energy of the composite electrode was calculated according to the equation:

$$
W=(1 / 2) \cdot Q_{S C} \cdot \Delta V_{S C}+Q_{B} \cdot V_{B}
$$

where the first and second term correspond to the energy of the supercapacitor response and the battery one, respectively. The first term of Eq. 3 is deduced from $(1 / 2) \cdot C_{S C} \cdot \Delta V_{S C}{ }^{2}$ and $C_{S C}=Q_{S C} / \Delta V_{S C}$

The specific power was calculated according to the equation:

$$
P=W /\left(t_{3}-t_{0}\right)
$$

where $t_{3}-t_{0}$ is the total time as discussed in Figure $5 \mathrm{~b}$. For the bare $\mathrm{CC}$, showing capacitive response only, the specific energy and specific power were also calculated.

The variation of the specific power vs. the specific energy for the $\mathrm{CoO}_{\mathrm{x}} / \mathrm{CC}$ composite is shown in Figure 7. For comparison, the results obtained for the bare $\mathrm{CC}$ are also shown. The maximum value of specific energy increases from $14 \mathrm{~W} \mathrm{~h} \mathrm{~kg}^{-1}$ for the bare $\mathrm{CC}$ to $24 \mathrm{~W} \mathrm{~h} \mathrm{~kg}^{-1}$ for the $\mathrm{CoO}_{\mathrm{x}} / \mathrm{CC}$ composite, pointing out the positive contribution of the deposited $\mathrm{CoO}_{\mathrm{x}}$ to increasing the composite energy. The maximum value of specific power, of ca. $1 \mathrm{~kW} \mathrm{~kg}^{-1}$, is similar for the $\mathrm{CoO}_{\mathrm{x}} / \mathrm{CC}$ composite and for the bare CC. This shows the dominance of the substrate to the composite power.

Regarding the cycling stability of the $\mathrm{CoO}_{\mathrm{x}} / \mathrm{CC}$ composite, the specific capacity, $Q_{E}$, remained at $82 \%$ of its initial value after 5,000 charge/discharge cycles. These measurements were carried out at the current density of $26 \mathrm{~mA} \mathrm{~cm}^{-2}$ or $2 \mathrm{~A} \mathrm{~g}^{-1}$.

\section{Conclusions}

Flexible composites made from battery and supercapacitor electrode materials were obtained by electrodeposition of $\mathrm{CoO}_{\mathrm{x}}$ on $\mathrm{CC}$, the latter acting as substrate. The electrodeposited $\mathrm{CoO}_{x}$ appears as sheets of ca. $4 \mathrm{~nm}$ in thickness and $60 \mathrm{~nm}$ in length. The sheets, showing an open structure, lay aggregated on the fibers of the carbon cloth.

The CC substrate shows electrochemical response of supercapacitor electrode. The deposited $\mathrm{CoO}_{\mathrm{x}}$ shows electrochemical response of battery electrode. By a procedure described in this study, the charge (capacity) associated with the two materials and with the complete electrode was determined. The proposed procedure can be applied as the two responses, supercapacitor and battery, appear differentiated in the GCD plots. This procedure involves less work and hence, is faster than the procedure based on $\mathrm{CV}$ measurements. The two procedures, $\mathrm{GCD}$ and $\mathrm{CV}$, provide similar results of charges (capacities). However, the procedure here reported cannot be applied when the two responses 
are not clearly differentiated, i.e. for battery-type electrodes in which a significant pseudocapacitive contribution appears as a consequence of the nanometer size of the electrode particles.

The electrodeposited $\mathrm{CoO}_{\mathrm{x}}$ enhances the capacity of the complete electrode as measured at low current densities. However, its contribution is negligible at high current densities. From the point of view of the specific energy and specific power of the composite as defined in this study, the composite shows higher energy than the CC substrate but the same power as the substrate.

\section{Acknowledgments}

Financial support through the project FCT-M-ERA-NET/0004/ 2014- PCIN2015-024 is gratefully acknowledged. Authors thank Prof. G. Z. Chen from the University of Nottingham (UK) for helpful discussions. We also thank J. A. Diaz from Carbongen SA, and R. Beneito and J. Vilaplana from AIJU for providing the bare carbon cloth.

\section{ORCID}

\section{J. M. Rojo (1D https://orcid.org/0000-0003-3392-2856}

\section{References}

1. S. Trasatti and G. Buzzanca, "Ruthenium dioxide: a new interesting electrode material. Solid state structure and electrochemical behavior", J. Electroanal. Chem., 29, 1 (1971).

2. B. E. Conway, Electrochemical Supercapacitors. Scientific Fundamentals and Technological Applications., Kluwer Academic. New York 1999.

3. L. Guan, L. Yu, and G. Z. Chen, "Capacitive and non-capacitive faradaic charge storage", Electrochim. Acta, 206, 464 (2016).

4. C. Costentin, T. R. Porter, and J. M. Saveant, "How do pseudocapacitors store energy? Theoretical analysis an experimental illustration", ACS Appl. Mater. Interfaces, 9, 8649 (2017)

5. M. Forghani and S. W. Donne, "Method comparison for deconvoluting capacitive and pseudo-capacitive contributions to electrochemical capacitor electrode behavior", $J$. Electrochem. Soc., 165(3), A664 (2018)

6. J. Wang, J. Polleux, J. Lim, and B. Dunn, "Pseudocapacitive contributions to electrochemical energy storage in $\mathrm{TiO}_{2}$ (anatase) nanoparticles", J. Phys. Chem. C, 111 14925 (2007)

7. V. Augustyn, P. Simon, and B. Dunn, "Pseudocapacitive oxide materials for high-rate electrochemical energy storage", Energy Environ. Sci., 7, 1597 (2014).

8. P. Simon, Y. Gogotsi, and B. Dunn, "Where do batteries end and supercapacitors begin?", Science, 343, 1210 (2014).

9. T. Brezesinski, J. Wang, S. H. Tolbert, and B. Dunn, "Ordered mesoporous $\alpha-\mathrm{MoO}_{3}$ with iso-oriented nanocrystalline walls for thin-film pseudocapacitors" Nature Mater. 9, 146 (2010)

10. J.-Y. Shin, D. Samuelis, and J. Maier, "Sustained lithium-storage performance of hierarchical nanoporous anatase $\mathrm{TiO}_{2}$ at high rates: Emphasis on interfacial storage phenomena", Adv. Funct. Mater, 21, 3464 (2011)

11. V. Agustyn, J. Come, M. A. Lowe, J. W. Kim, P. L. Taberna, S. H. Tolbert, H. D. Abruña, P. Simon, and B. Dunn, "High-rate electrochemical energy storage through $\mathrm{Li}^{+}$intercalation pseudo capacitance", Nature Mater. 12, 518 (2013).

12. Q. Mahmood, S. K. Park, K. D. Kwon, S.-J. Chang, J.-Y. Hong, G. Shen, Y. M. Jung, T. J. Park, S. W. Khang, W. S. Kim, J. Kong, and H. S. Park, "Transition from diffusion-controlled intercalation into extrinsically pseudocapacitive charge storage of $\mathrm{MoS}_{2}$ by nanoscale heterostructuring", Adv. Energy Mater., 6, 1501115 (2016).

13. V. Srinivasan and J. W. Weidner, "An electrochemical route for making porous nickel oxide electrochemical capacitors", J. Electrochem. Soc.,114, L210 (1997).

14. C. Lin, J. A. Ritter, and B. N. Popov, "Characterization of sol-gel-derived cobalt oxide xerogels as electrochemical capacitors”, J. Electrochem. Soc., 145, 4097 (1998).

15. H.-K. Kim, T.-Y. Seong, J.-H. Lim, W. I. Cho, and Y. S. Yoon, "Electrochemical and structural properties of radio frequency sputtered cobalt oxide electrodes for thin-film supercapacitors", J. Power Sources, 102, 167 (2001).

16. L. Cao, M. Lu, and H.-L. Li, "Preparation of mesoporous nanocrystalline $\mathrm{Co}_{3} \mathrm{O}_{4}$ and its applicability of porosity to the formation of electrochemical capacitance", J. Electrochem. Soc., 152, A871 (2005).

17. V. R. Shinde, S. B. Mahadik, T. P. Gujar, and C. D. Lokhande, "Supercapacitive cobalt oxide $\left(\mathrm{CO}_{3} \mathrm{O}_{4}\right)$ thin films by spray pyrolysis", Appl. Surf. Sci., 252, 7487 (2006).

18. S. Xiong, C. Yuan, X. Zhang, B. Xi, and Y. Qian, "Controllable synthesis of mesoporous $\mathrm{Co}_{3} \mathrm{O}_{4}$ nanostructures with tunable morphology for application in supercapacitors", Chem. Eur. J., 15, 5320 (2009).

19. L. Cui, J. Li, and X.-G. Zhang, "Preparation and properties of $\mathrm{Co}_{3} \mathrm{O}_{4}$ nanorods as supercapacitor material", J. Appl. Electrochem., 39, 1871 (2009).

20. G. Wang, X. Shen, J. Horvat, B. Wang, H. Liu, D. Wexler, and J. Yao, "Hydrothermal synthesis and optical, magnetic, and supercapacitance properties of nanoporous cobalt oxide nanoroads", J. Phys. Chem. C, 113, 4357 (2009).
21. Y. Gao, S. Chen, D. Cao, G. Wang, and J. Yin, "Electrochemical capacitance of $\mathrm{Co}_{3} \mathrm{O}_{4}$ nanowire arrays supported on nickel foam", J. Power Sources, 195, 1757 (2010).

22. J. Liu, J. Jiang, C. Cheng, H. Hongxing, J. Zhang, H. Gong, and H. J. Fan, " $\mathrm{Co}_{3} \mathrm{O}_{4}$ nanowire@ $\mathrm{MnO}_{2}$ ultrathin nanosheet core/shell arrays: A new class of highperformance pseudocapacitive materials", Adv. Mater, 23, 2076 (2011).

23. L. Wang, X. Liu, X. Wang, X. Yang, and L. Lu, "Electrochemical capacitance study on $\mathrm{Co}_{3} \mathrm{O}_{4}$ nanowires for supercapacitors application", J. Mater. Sci.: Mater Electron, 22, 601 (2011).

24. W.-J. Zhou, M.-W. Xu, D.-D. Zhao, C.-L. Xu, and H.-L. Li, "Electrodeposition and characterization of ordered mesoporous cobalt hydroxide films on different substrates for supercapacitors", Micopor. Mesopor. Mater., 117, 55 (2009).

25. J. B. Wu, Y. Lin, X. H. Xia, J. Y. Xu, and Q. Y. Shi, "Pseudocapacitive properties of electrodeposited porous nanowall $\mathrm{Co}_{3} \mathrm{O}_{4}$ film", Electrochim. Acta, 56, 7163 (2011).

26. S. G. Kandalkar, H.-M. Lee, H. Chae, and C.-K. Kim, "Structural, morphological and electrical characteristics of electrodeposited cobalt oxide electrode for supercapacitor applications", Mater. Res. Bull., 46, 48 (2011).

27. Y. F. Yuan, X. H. Xia, J. B. Wu, X. H. Huang, Y. B. Pei, J. L. Yang, and S. Y. Guo, "Hierarchically porous $\mathrm{Co}_{3} \mathrm{O}_{4}$ film with mesoporous walls prepared via liquid crystalline template for supercapacitor application", Electrochem. Commun., 13, 1123 (2011).

28. C.-W. Kung, H.-W. Chen, C.-Y. Lin, R. Vittal, and K.-C. Ho, "Synthesis of $\mathrm{Co}_{3} \mathrm{O}_{4}$ nanosheets via electrodeposition followed by ozone treatment and their application to high performance supercapacitors", J. Power Sources, 214, 91 (2012).

29. M. Aghazadeh, "Electrochemical preparation and properties of nanostructured $\mathrm{Co}_{3} \mathrm{O}_{4}$ as supercapacitor material", J. Appl. Electrochem., 42, 89 (2012).

30. Y.-L. Wang, Y.-Q. Zhao, and C.-L. Xu, "May 3D nickel foam electrode be the promising choice for supercapacitors?", J. Solid State Electrochem., 16, 829 (2012).

31. F. S. Fedorov, J. Linnemann, K. Tschulik, L. Giebeler, M. Uhlemann, and A. Gebert, "Capacitance performance of cobalt hydroxide-based capacitors with utilization of near-neutral electrolytes", Electrochim. Acta, 90, 166 (2013).

32. A. J. Jagadale, V. S. Kumbhar, R. N. Bulakhe, and C. D. Lokhande, "Influence of electrodeposition modes on the supercapacitive performance of $\mathrm{CO}_{3} \mathrm{O}_{4}$ electrodes", Energy, 64, 234 (2014)

33. G. Nagaraju, Y. H. Ko, and J. S. Yu, "Tricobalt tetroxide nanoplate arrays on flexible conductive fabric substrate: Facile synthesis and application for electrochemical supercapacitors", J. Power Sources, 283, 251 (2015).

34. N. Abushrenta, X. Wu, J. Wang, J. Liu, and X. Sun, "Hierarchical Co-based porous layered double hydroxide arrays derived via alkali etching for high performance supercapacitors", Sci. Rep., 5, 13082 (2015).

35. M. Fan, B. Ren, L. Yu, D. Song, Q. Liu, J. Liu, J. Wang, X. Jing, and L. Liu, "Facile synthesis of $\mathrm{Co}_{3} \mathrm{O}_{4}$ nanowires grown on hollow $\mathrm{NiO}$ microspheres with superior electrochemical performance", Electrochim. Acta, 166, 168 (2015).

36. A. Garcia-Gomez, R. G. Duarte, S. Eugenio, T. M. Silva, M. J. Carmezim, and M. F. Montemor, "Fabrication of electrochemically reduced graphene oxide/cobalt oxide composites for charge storage electrodes", J. Electroanal. Chem., 755, 151 (2015).

37. D. S. Dhawale, G. P. Mane, S. Joseph, S. N. Talapaneni, C. Anand, A. Mano, S. S. Aldeyab, K. S. Lakhi, and A. Vinu, "Cobalt oxide fuctionalized nanoporous carbon electrodes and their excellent supercapacitive performance", $R S C A d v . \mathbf{5}$, 13930 (2015).

38. Q. Liao, N. Li, S. Jin, G. Yang, and C. Wang, "All-solid-state symmetric supercapacitor based on $\mathrm{Co}_{3} \mathrm{O}_{4}$ nanoparticles on vertically aligned graphene", ACS Nano, 9 , 5310 (2015).

39. N. Iqbal, X. Wang, J. Ge, J. Yu, H.-Y. Kim, S. S. Al-Deyab, M. El-Newehy, and B. Ding, "Cobalt oxide nanoparticles embedded in flexible carbon nanofibers: attractive material for supercapacitor electrodes and $\mathrm{CO}_{2}$ adsorption", $R S C$ Adv. 6, 52171 (2016).

40. T. T. Nguyen, V. H. Nguyen, R. K. Deivasigamani, D. Kharismadewi, Y. Iwai, and J.-J. Shim, "Facile synthesis of cobalt oxide/reduced graphene oxide composites for electrochemical capacitor and sensor applications", Solid State Sciences, 53, 71 (2016).

41. S. Aloqayli, C. K. Ranaweera, Z. Wang, K. Siam, P. K. Kahol, O. N. Srivastava, B. K. Gupta, S. R. Mishra, F. Perez, X. Shen, and R. K. Gupta, "Nanostructured cobal oxide and cobalt sulfide for flexible, high performance and durable supercapacitors", Energy Storage Mater. 8, 68 (2017).

42. S. Sahoo and A. K. Satpati, "Electrochemical capacitance properties of cobalt oxide entangled over MWCNT and cobalt oxide AC composites", J. Electroanal. Chem., 801, 416 (2017)

43. A. A. Yadav and U. J. Chavan, "Electrochemical supercapacitive performance of spray deposited $\mathrm{Co}_{3} \mathrm{O}_{4}$ thin film nanostructures", Electrochim. Acta, 232, 370 (2017).

44. T. Brousse, D. Belanger, and J. W. Long, "To be or not to be pseudocapacitive", J. Electrochem. Soc., 162, A5185 (2015).

45. I. Aldama, V. Barranco, T. A. Centeno, J. Ibañez, and J. M. Rojo, "Composite electrodes made from carbon cloth as supercapacitor material and manganese and cobalt oxide as battery one", J. Electrochem. Soc., 163, A758 (2016).

46. Y. Gogotsi and R. M. Penner, "Energy storage in nanomaterials-Capacitive, pseudocapacitive or battery-like?" ACS Nano, 12, 2081 (2018).

47. S. Kong, F. Yang, K. Cheng, T. Ouyang, K. Ye, G. Wang, and D. Cao, "In-situ growth of cobalt oxide nanoflakes from cobalt nanosheet on nickel foam for battery-type supercapacitors with high specific capacity", J. Electroanal. Chem., 785, 103 (2017).

48. G. Godillot, P.-L. Taberna, B. Daffos, P. Simon, C. Delmas, and L. Guerlou-Demourgues, "High power density aqueous hybrid supercapacitor combining activated carbon and highly conductive spinel cobalt oxide", J. Power Sources, 331, 277 (2016) 
49. T. Nguyen, M. Boudard, M. J. Carmezim, and M. F. Montemor, "Layered Ni(OH $)_{2-}$ $\mathrm{Co}(\mathrm{OH})_{2}$ films prepared by electrodeposition as charge storage electrodes for hybrid supercapacitors", Sci. Rep., 7, 39980 (2017).

50. J. Niu, W. G. Pell, and B. E. Conway, "Requirements for performance characterization of $\mathrm{C}$ double layer supercapacitors: Applications to a high specific-area C-cloth material". J. Power Sources, 156, 725 (2006).

51. A. G. Pandolfo and A. F. Hollenkamp, "Carbon properties and their role in supercapacitors". J. Power Sources, 157, 11 (2006).

52. M. Inagaki, H. Konno, and O. Tanaike, "Carbon materials for electrochemical capacitors". J. Power Sources, 195, 7880 (2010).

53. I. Aldama, V. Barranco, M. Kunowsky, J. Ibañez, and J. M. Rojo, "Contribution of cations and anions of aqueous electrolytes to the charge stored at the electric electrolyte/electrode interface of carbon-based supercapacitors", J. Phys. Chem. C, 121, 12053 (2017).

54. Y.-C. Chen, Y.-K. Hsu, Y.-G. Lin, Y.-K. Lin, Y.-Y. Horng, L.-C. Chen, and K.-H. Chen, "Highly flexible supercapacitors with manganese oxide nanosheet/carbon cloth electrode", Electrochim. Acta, 56, 7124 (2011).

55. K. Jost, D. Stenger, C. R. Perez, J. K. McDonough, K. Lian, Y. Gogotsi, and G. Dion, "Knitted and screen printed carbon-fiber supercapacitors for applications in wearable electronics", Energy Environ. Sci., 6, 2698 (2013).

56. L. Bao and X. Li, "Towards textile energy storage from cotton T-shirts", Adv. Mater, 24, 3246 (2012)

57. L. Kou, T. Huang, B. Zheng, Y. Han, X. Zhao, K. Gopalsamy, H. Sun, and C. Gao, "Coaxial wet-spun yarn supercapacitors for high-energy density and safe wearable electronics", Nat. Commun.,5, 3754 (2014).

58. Y.-Y. Horng, Y.-C. Lu, Y.-K. Hsu, C.-C. Chen, L.-C. Chen, and K.-H. Chen, "Flexible supercapacitor based on polyaniline nanowires/carbon cloth with both gravimetric and area-normalized capacitance", J. Power Sources, 195, 4418 (2010).

59. J. Xu, Q. Wang, X. Wang, Q. Xiang, B. Liang, D. Chen, and G. Shen, "Flexible asymmetric supercapacitors based upon $\mathrm{Co}_{9} \mathrm{~S}_{8}$ nanorod $/ / \mathrm{Co}_{3} \mathrm{O}_{4} @ \mathrm{RuO}_{2}$ nanosheet arrays on carbon cloth", ACS Nano, 7, 5453 (2013).

60. G. Xiong, C. Meng, R. G. Reifenberger, P. P. Irazoqui, and T. S. Fisher, "Graphitic petal electrodes for all-solid-state flexible supercapacitors", Adv. Energy Mater., 4, 1300515 (2014)

61. Y. Zhang, Z. Hu, Y. Liang, Y. Yang, N. An, Z. Li, and H. Wu, "Growth of $3 \mathrm{D} \mathrm{SnO}_{2}$ nanosheets on carbon cloth as a binder-free electrode for supercapacitors", J. Mater. Chem. A, 3, 15057 (2015).

62. S. He and W. Chen, "Application of biomass-derived flexible carbon cloth coated with $\mathrm{MnO}_{2}$ nanosheets in supercapacitors", J. Power Sources, 294, 150 (2015).

63. Z. Pan, Y. Qiu, J. Yang, F. Ye, Y. Xu, X. Zhang, M. Liu, and Y. Zhang, "Ultra-endurance flexible all-solid-state asymmetric supercapacitors based on threedimensionally coated $\mathrm{MnO}_{\mathrm{x}}$ nanosheets on nanoporous current collectors", Nano Energy, 26, 610 (2016).

64. Z.-H. Huang, Y. Song, X.-X. Xu, and X.-X. Liu, "Ordered polypyrrole nanowire arrays grown on a carbon cloth substrate for high performance pseudocapacitor electrode", ACS Appl. Mater. Interfaces, 7, 25506 (2015).

65. J. M. Sieben, E. Morallon, and D. Cazorla-Amoros, "Flexible ruthenium oxideactivated carbon cloth composites prepared by simple electrodeposition methods", Energy, 58, 519 (2013).

66. F. Pico, E. Morales, J. A. Fernandez, T. A. Centeno, J. Ibañez, R. M. Rojas, J. M. Amarilla, and J. M. Rojo, "Ruthenium oxide/carbon composites with microporous or mesoporous carbon as support and prepared by two procedures. A comparative study as supercapacitor electrodes", Electrochim. Acta, 54, 2239 (2009). 